\title{
An Analysis of Subtitle Translation of Hello, Mr. Billionaire from the Perspective of Skopos Theory
}

\author{
Yucheng Sheng, Xiaohui Gao, Honglei Ma, Yaorui Zhuang \\ Fujian Normal University, Fuzhou, China \\ Email:1656059066@qq.com
}

How to cite this paper: Sheng, Y.C., Gao, X.H., Ma, H.L. and Zhuang, Y.R. (2019) An Analysis of Subtitle Translation of Hello, Mr. Billionaire from the Perspective of Skopos Theory. Open Access Library Journal, 6: e5591.

https://doi.org/10.4236/oalib.1105591

Received: July 9, 2019

Accepted: July 23, 2019

Published: July 26, 2019

Copyright $\odot 2019$ by author(s) and Open Access Library Inc.

This work is licensed under the Creative Commons Attribution International License (CC BY 4.0).

http://creativecommons.org/licenses/by/4.0/

\begin{abstract}
As a significant medium of cross-culture communication, film subtitle translation should be attached more importance to for the sake of better implementing Chinese Culture Going Global Strategy. Appropriate subtitle translation can accurately convey cultural connotations and facilitate cross-cultural communication, while inappropriate subtitle translation may cause flavor loss or even lead to serious misunderstandings. Therefore, subtitle translation is of great importance. In order to improve subtitle translation in Chinese comedy and boost cultural communication in the world, this article makes an analysis of subtitle translation of Hello, Mr. Billionaire, a typical Chinese comedy gaining popularity and praise, from the perspective of skopos theory and provides suggestions for subtitle translation improvements.
\end{abstract}

\section{Subject Areas \\ Linguistics, Literature}

\section{Keywords}

Subtitle Translation, Skopos Theory, Hello, Mr. Billionaire

\section{Introduction}

At the start of the $21^{\text {st }}$ century, with the growth of globalization, the cross-cultural communication is becoming more and more frequent and important. Besides, due to the great improvement of our living standards, we are paying more and more attention to our spiritual life. Thus, film has gradually become an indispensable part of our daily life. Nowadays, lots of foreign films are imported into China each year. In the meantime, with the promotion of China's 
international status and the implementation of reform and opening-up, home-made films are going globally. It is known to all that China boasts a long history and profound culture, and Chinese comedy is essentially the combination of a part of reflection on diversified Chinese cultures and recreation with artistic effects. Because of its unique style, Chinese comedy has attracted both domestic and foreign audiences. However, cultural differences bring about barriers for foreign audiences to understand the content completely and accurately. To help them better grasp the original meaning, high requirements have been set on the subtitle translation, which may act as a booster for culture transmission by keeping in pace with the trend. In recent years, skopos theory has been widely applied in translation, which has realized great achievements in some fields, such as politics, economy, diplomacy, and education, etc. While in film, it has seldom been studied and applied.

According to skopos theory, the purpose of translation determines the means of translation. The case analysis method is used to analyze subtitle translation of Hello, Mr. Billionaire in this essay, which aims at summarizing the characteristics of subtitle translation and pointing out its limitations and assisting us in coming up with suggestions for more precise subtitle translation. Hello, Mr. Billionaire, shown in the last year, is one of the most popular Chinese comedies. This paper retrospects the classic comedy and further studies its subtitle translation to better disseminate Chinese culture abroad.

\section{Subtitle Translation}

\subsection{Definition of Subtitle and Subtitle Translation}

The Oxford Advanced Learner's English-Chinese Dictionary (6th Edition) (2004: p. 1763) [1] defines subtitle as "words that translate what is said in a film/movie into a different language and appear on the screen at the bottom". Acoording to Mark Shuttleworth and Moira Cowie, Subtitling can be defined as "the process of providing synchronized captions for film and television dialogue and more recently for live opera" (Shuttle \& Cowie, 2014: p. 161) [2]. Subtitle translation can be regarded as a written, immediate, and synchronous translation. According to these definitions, it can be concluded that subtitle translation refers to giving interpretations of the original words appearing at the bottom of the film or television screen.

The main function of subtitle translation is to convey the precise message to the audience in an effective way and make them understand and appreciate the film and television limited by time and space. In order to achieve this goal, translators must obey some principles and adopt some techniques and strategies, as well as lay much emphasis on the cultural phenomenon.

\subsection{Features of Subtitle Translation}

Different from novel and poetry translation, which is more static and literary, subtitle translation is more colloquial because they interpret the original dialo- 
gues among characters. Therefore it must possess typical features of spoken English without involving obscure expressions or complex sentence patterns.

The language used in subtitle translation must be simple and plain so that ordinary people can understand completely and amuse themselves. Zhang Chunbai encourages translators to try their best to translate the dialogues which can be understood by most of the reviewers no matter the educated or the illiteracy (Zhang, 2003: p. 183) [3].

Readers of printed literary works may have opportunities to read the works repeatedly. In contrast, dialogues and subtitles will only stay on the screen for a few seconds. Given time for understanding the information is limited, subtitle translation should be with instantaneity and brevity.

\subsection{Previous Studies on Subtitle Translation}

\subsubsection{Previous Studies on Subtitle Translation Abroad}

Western scholars are the pioneers in studying subtitle translation. In 1960, a paper on subtitle translation, published on Babel title Cinema and et Translation, is considered to be the first paper studying subtitle translation, opening a new field of subtitle translation study.

In 1974, Cay Dollerup, a professor from University of Copenhagen, issued an essay On Subtitles in Television Program (Dollerup, 1974) [4], which pointed out not only different kinds of mistakes occurred during the process of translating English TV programs into Danish subtitles, but also the significance of subtitles. The essay really drew public attention to subtitle translation.

In 1976, Istva Fodor, a renowned scholar in the field of western subtitle translation, published Film Dubbing. Phonetic, Semiotic, Esthetic and Psychological Aspects (Fodor, 1976) [5], which laid the foundation of western subtitle translation study.

In the following ten years, the study on translation was not so popular. In 1987, an international conference on dubbing and subtitle translation hosted by European Broadcasting Union was held in Stockholm. It was the first open talk about dubbing and subtitling in Europe. This conference encouraged scholars to hold a series of conferences about subtitle translation. After that, numerous publications on film translation came out.

The study on subtitle translation in Europe reached its peak in the early 1990s. For instance, Overcoming Language Barriers in Television: Dubbing and Subtitling for European Audience (Luyken and Thomas, 1991) [6] came out, in which scholars analyzed different translation forms of television programs and enumerated numerous data. In 1992, Jonas Ivarsson, a Swedish subtitle translator published Subtitling for the Media: A Handbook of an Art (Ivarsson, 1992) [7], in which he analyzed subtitle translation from a technical perspective. These books laid a solid foundation for further study on subtitle translation.

In 1995, ESIST (European Association in Screen Translation) was founded and since then, audiovisual translation began to have a mature development in Europe. The number of published papers increased noticeably. (Multi) Media 
Translation: concepts, practices, and research (Yves Gambier \& Henrik Gottlieb, 2001) [8] is the first collection of papers on subtitle translation. In the introduction part, the authors put forward the view that the research methods and translation strategies about subtitle translation should be different from those on traditional texts' translation.

Admittedly, western scholars are the leading figures in the field of subtitle translation. At many universities in Europe, there are quite a few majors and courses for studying film and television subtitle translation.

\subsubsection{Previous Studies on Subtitle Translation in China}

Compared with western countries, the study on film and television translation in China started late and developed slowly. There are few theoretical work systematically discussing subtitle translation at home. Seminars and organizations on subtitle translation are also few in number. We have only a few translators and scholars putting forward several influential theories. Qian Shaochang, Ma Zhengqi are well-known scholars who have made great achievements in the filed of translation practice.

Processor Qian Shaochang is regarded as the pioneer in the fields of domestic film translation. In the paper Audio-visual Translation-an Increasingly Important Field in the Garden of Translation (Qian, 2000) [9], he emphasized the significance of film subtitle translation, and delved into the linguistic differences between film and literature works. He also summarized three principles of film subtitle translation that are faithfulness, expressiveness and elegance.

Professor Ma Zhengqi, having committed himself to subtitle translation for almost 30 years, has translated more than 50 movies and TV series for the CCTV programs "International Cinema" and "Zhengda Theatre".

These professors have paved the way for domestic study of subtitle translation and encouraged more researchers to pay attention to this field. However, compared with western countries, our studies in the field of subtitle translation practice and theoretical work still lag far behind. Therefore, more and more scholars and translators should devote themselves to this field and produce more creative and practical research results.

\section{Skopos Theory}

As one of the most important translation theories, skopos theory regards the process of translation as a communicative activity and human action. Skopos theory, originated from modern functionalism in translation study, attaches great importance to the targeted readers of the translated version of certain texts. To have a better grasp of skopos theory, in this chapter, we will explore the origin and development of skopos theory and the fundamental rules attached to it.

\subsection{Origin of Skopos Theory}

“Skopos is a Greek word for 'aim' or 'purpose' and was introduced into translation theory by Vermeer as a technical term for the purpose of a translation and 
the action of translating" (Munday, 2001: p. 78) [10]. Skopos theory was coined by the German scholar Han J. Vermeer in 1978, who believes that the purpose or skopos of overall translation action act as the fundamental principle for any translation process.

\subsection{Development of Skopos Theory}

As we know, skopos theory was originally put forward by Han J. Vermeer in the 1970s. From then on, translation has gradually been regarded as a cross-culture communication activity rather than a static linguistic phenomenon. With the improvement of modern functionalist in translation studies, functionalist approach has gone through four stages in its development.

\subsubsection{Text Typology}

The concept of text typology was created by Katharina Reiss in her book Translation Criticism: the Potential and Limitations. Katharina Reiss believed that equivalence should be achieved at text level rather than at the word or sentence level, so that the readers can make it possible that they understand the translated version of the text effectively and efficiently. In addition, Reiss further classified the concept of text types as content-focused text, form-focused text, appeal-focused text and audio-media text.

\subsubsection{Skopos Theory}

The concept of skopos theory was put forward by Hans J. Vermeer based on action theory. Vermeer regarded translation process as a special form of human action, "which is an intentional, purposeful behavior that takes place in a given situation; it is part of the situation at the same time it modifies the situation" (Nord, 2001: p. 11) [11]. Thus, the purpose of translation action exerts huge influence on circumstances.

\subsubsection{Translational Action}

On the basis of text typology and skopos theory, Justa Holz Manttari put forward the concept of translational action. "The purpose of translational action is to transfer messages across culture and language barriers by means of message transmitters produced by experts" (Nord 2001: p. 13) [11]. That is, according to translational action theory, the translator is at the superior position while the source text is at the inferior position. Therefore, source text is merely a tool to make communication happen without any set values and they can be translated in different ways to meet the interest of the TT receivers.

\subsubsection{Function Plus Loyalty}

Although skopos translation theory gained much popularity in academic realm, Nord believed that there were still two limitations remaining to be improved. "One concerns the culture-specificity of translational models; the other has to do with the relationship between the translator and the source-text author" (Nord 2001: 124) [11]. Therefore, Nord takes further steps to perfect the theory by adding function plus loyalty principle to it. According to Nord, the translated 
text should be able to "function the situation in which it is used and with the people who want to use it and precisely in the way they want it function" (Nord, 2001: p. 29) [11]. Loyalty refers to the relationship between the author, the translator and the reader.

\subsection{The Three Basic Rules of Skopos Theory}

\subsubsection{Skopos Rule}

Different from the conventional translation theories that attach great importance to fidelity or equivalence or the functions of source text on target text readers, skopos theory gives top priority to the skopos of the target text, which determines the overall process of translation. Thus, skopos rule acts as the leading rule guiding the translation process among the three rules. Vermeer explained it in a right way: Each text is produced for a given purpose and should serve this purpose. The skopos rule thus reads as follows: Translate/interpret/speak/write in a way that enables your text translation to function in the situation in which it is used and with the people who want to use it and precisely in the way they want it function.(Nord, 2001: p. 29) [11] In conclusion, Translator should always bear translational purpose in their mind whatever translation methods or strategies he chooses.

\subsubsection{Coherence Rule}

The coherence rule states that the TT "must be interpreted as coherence with the TT receiver's situation" (Reiss and Vermeer, 1984: p. 113) [12]. A successful communicative interaction can only be achieved under the condition that the translated version of the text is acceptable and meaningful for targeted receivers. Coherence Rule "specifies that a translation should be acceptable in a sense that it is coherent with the receiver's situation" (Nord, 2001: p. 32) [11].

\subsubsection{Fidelity Rule}

Different from the coherence rule, which focuses on the relationship between the target text and the targeted context, fidelity rule, also called intertextual coherence, refers to the relationship between source text and target text. It stipulates that in the process of translation, the translator should take both source text and target text into consideration. To some extent, fidelity rule resembles the claim that "translation should be faithful in some traditional translation theories except in that the degree or the form of fidelity in skopos theory changes with skopos" (qtd. in Zhang, 2016: p. 15) [13].

\section{Application of Skopos Theory to Subtitle Translation of Hello, Mr. Billionaire and Suggestions for Improvement}

\subsection{Analysis of Subtitle Translation of Hello, Mr. Billionaire Based on Skopos Theory}

\subsubsection{Analysis of Subtitle Translation from Skopos Rule}

Skopos rule refers to the prime principle in translation act, meaning that 
translation act is determined by its purpose, aim or skopos. According to skopos theory, the translator should not only pay attention to the target language and culture, but also take the readers' responses into consideration. Here is an example based on skopos rule in the film Hello, Mr. Billionaire:

Original: 我这不担心你怕你想不开吗?

Translation: I just worried that you will commit suicide.

This sentence occurs in the first scene of the film when Wang Duoyu loses in the football match. Knowing that Duoyu is feeling upset, Duoyu's best friend Zhuang Qiang calls him, but his phone is out of service. Zhuang Qiang is so worried that he breaks into Duoyu's door directly, but only to find that Duoyu is installing a bulb. Seeing that the door is broken, Duoyu demands his friend to pay for the damage. Then Zhuang Qiang explains that it is because that he is so worried that Duoyu will commit suicide. This subtitle translation follows the Skopos rule. Instead of using the method of literal translation which would make the audiences confused, the translator adopts the principle of Skopos rule, making the contents simple and easy to understand.

\subsubsection{Analysis of Subtitle Translation from Coherence Rule}

Coherence rule demands that the target text should be suitable for or at least make sense for the target readers. The coherence rule means that "message or target text produced by the translator should be comprehensible and meaningful in a way that it's coherent with the target readers' reaction or feedback. It shows that the target text has been well appreciated and the interaction has also been achieved" (Shuttle \& Cowie, 2004:19) [2]. Here is an example:

Original: 点再背也总该有个头吧, 我也该走走运了吧。

Translation: Bad luck will come to an end, good luck will come to me.

This sentence conveys Duoyu's dissatisfaction with his current situation and his wish to live a better life. Since the translation text is coherent with the target context, the receivers can easily understand the sentence. Thus, it is fair to say that this translation is acceptable in that it is coherent with the receiver's situation.

\subsubsection{Analysis of Subtitle Translation from Fidelity Rule}

Fidelity rule refers to the situation that the target text should be faithful to original text. Different from the principle of faithfulness in some traditional translation theories, the fidelity rule demands that the extent of fidelity and forms should rely on the skopos of the translation. Here is an example to illustrate this rule:

Original: 滚蛋

Translation: Go to hell

In this example, if we adopt the strategy of literary translation, “滚蛋” should be translated into "rolling eggs", which would definitely confuse the audiences because it is not faithful for the original text. "go to hell" is a much better choice as it properly conveys intended message to express Duoyu's anger. 


\subsection{Translation Methods in Subtitle Translation of Hello, Mr. Billionaire}

\subsubsection{Reduction}

As subtitle translation is restricted by time and space, it should not be too long. Subtitle translators should try to make the length of the original text and subtitle translation the same. Vermeer reckons that any text is just "an offer of information" from which receivers select the information they find interesting and important. (Nord, 2001: p. 31) [11] Therefore, it's necessary to delete redundant information in order to make the translation more concise and readable, which is a goal skopos theory always pursue for. Chinese people like to use four-character idioms during the conversation, but translation of these expressions should not be very long, otherwise they would be improper in the subtitle translation. Here are some examples.

1) Original: 双喜临门。

Translation: Double happiness.

When Duoyu is dismissed by the coach of the football team, Wang Duoyu's friend Zhuang Qiang defends him against the justice by threatening the coach that he himself will quit too. It's surprising that the coach do dismiss Zhuang Qiang and even acclaim it as “双喜临门”. In the original text, “双喜临门” means two good news come to a family at the same time. “临门” means "happen to the family" because Chinese people would put the traditional Chinese character “喜” onto the door when there is a marriage. It is obvious that the core meaning of the phrase lays on the first two characters “双喜”, so we can omit “临门” in subtitle translation to make subtitles more concise.

2) Original: 咱先礼后兵

Translation: Let's sort out with peace first.

“先礼后兵” is usually translated into "courteous before the use of force" or "being a gentleman first and a soldier second", which both place “礼” “兵” on the equal importance in translation. Considering the brevity and length of the subtitle, the translator puts more emphasis on the translation of “礼” to pursue harmony. It is used to make a bargain based on the essential rules in the scene. The following plots explain why we should be polite first and point out the possible future destruction.

3) Original: 集中火力干事业

Translation: I have to concentrate on the business,

In order to avoid redundancy, “火力” can be omitted because it isn't significant here. If it is added to the translation, this sentence will not comply with the thinking pattern of target audiences, easily causing puzzlement. In a way, a kind of omission used in translation is conductive to expressing the original meaning and generating a better understanding for foreign audiences.

\subsubsection{Paraphrase}

In this film, there are some proverbs, idioms, slang featuring northern dialect flavor which increase the intimacy and acceptance of Chinese audience but may 
bring up challenge for the foreign audience to understand. And according to the coherence rule of skopos theory, a translation should be coherent with the receivers' situation, so the subtitle translators use the strategy of paraphrase to foster intercultural understanding. In Baker's opinion, paraphrase is "a term for loose rewording, saying in one's own words" (Baker, 2004: p. 166) [1]. And according to skopos theory, the subtitles should have the same implication and function as the original text. Instead of literal translation, subtitle translators should translate freely by explaining and rewording meaning of expressions. There are several examples.

1) Original: 我差不点就嗝屁了。

Translation: I was almost dead.

“嗝屁” is a slang that means “dead”. It derives from the northern dialect, but it is often used to call one's name and seldom used in formal occasions. Here Wang Duoyu's great-uncle expresses strong disgust at his grandson playing women's football so he uses such an offensive expression. Here the translator directly translates the true meaning of “嗝屁” so that foreign audience would easily understand the dialogue and overcome cultural differences.

2) Original: 天无绝人之路。

Translation: There is always a way out.

When Wang Duoyu and his friend Zhuang Qiang are fired by the coach, they feel depressed, but Wang Duoyu still tries to remain hopeful and positive and utters this sentence. In the original text, “天” means "sky” in Chinese, which implies the whole world. It is a proverb in Chinese which means that though someone is in trouble for the moment, he will find a solution ultimately. If the translator translates the Chinese character “天” to "the sky" or the "the whole world", the proverb would be too concrete to express its original abstract beauty, which violates the fidelity rule of skopos theory. Therefore, subtitle translator adopts the method of paraphrase to present the true meaning.

3) Original: 我这不担心你怕你想不开么。

Translation: I just worried that you will commit suicide.

Original: 多鱼你也想开点。

Translation: Duoyu, take it easy.

“想不开” and “想开点” are two Chinese idioms. The former one means that some one want to end his life because of failure or adversity, while his friend may use the latter one to cheer him up and encourage him to be more positive. Apparently it will be ridiculous to do word-for-word translation like "can't think out" and "think out a bit". If so, foreign audience may misunderstood the meaning as "unable to find out the right solution" and "having made a little progress in finding out the truth of something", which also goes against the fidelity rule of skopos theory. Thus the subtitle translator paraphrases the idiom “想不开” into “commit suicide” and “想开点” into “take it easy”, which presents the true meaning well and foster the intercultural understanding.

4) Original: 你恢复一下。 
Translation: Buddy, you are so close to boss Wang.

It has completely changed the literal meaning according to the specific situation. Before knowing Wang Duoyu's fortune, the hotel manager behaves arrogantly, typical of a disgusting snob. After realizing his identity and assets, the manager's attitude is totally different, and he always bow obsequiously. This sort of hypocrisy dose make Duoyu uncomfortable, so he wants him to restore his arrogant face. Therefore, the translator has figured out the implied meaning and managed to show it by the oral expression.

5) Original: 那我就能甩开膀子干了。

Translation: Then I will do whatever I want.

It involves “甩开膀子”, a phrase with Chinese characteristics, which means sparing no efforts to do something no matter of any difficulty or adversity. Wang Duoyu is not a literary man but a vulgar with a large amount of money from the surprising inheritance. The translation is exactly consistent with the utterance style of him, and it accurately expresses the original meaning in a foreign manner.

6) Original: 就怕你这后院起火。

Translation: I'm worried there'll be a family conflict.

Original: 谁是你后院?

Translation: I am not your family?

“后院起火” is a Chinese idiom, referring to the terrible and thorny internal conflict. Due to the following response, a rhetorical question, the translator skillfully transfers it into a family conflict through observing the skopos, coherence and fidelity rule of the skopos theory. It dose give detailed explanation of the special phrase, and at the same time, it reduces receivers' confusion in a way.

7) Original: 把钱花在刀把上。

Translation: Spend money on minor business.

Original: 刀背上。

Translation: and marginal business.

It is admitted that focusing on the most important thing is a kind of wisdom, however, spending money on insignificant things here is contrary in the purpose of creating comic effects. In general, the essential thing in Chinese should be “刀 刀” instead of “刀把” “刀背”. Combining the whole story, Wang Duoyu constantly invests money in sunset business of diversified areas. Therefore, it is proper to associate the translation with business, promoting integral understanding.

8) Original: 那不完犊子了吗?

Translation: It will be a disaster.

“完犊子” belongs to northeast dialect, and it often indicates that a person or an event doesn't reach an expected effect or realize the ultimate purpose. It is not easy for foreigners to understand because of its Chinese features, so translating the true meaning is available and necessary.

9) Original: 这问题问得我措手不及。 
Translation: The question caught me on the hop.

Wang Duoyu invites Xia Zhu to enjoy the firework with him during her birthday. Surprised and moved, Xia bursts into tears and asks Wang whether he loves her. In fact, Wang just wants to use up 1 billion yuan as early as possible. Hearing what Xia has said, Wang is shocked and feels hard to answer her instantly. In the original text, “措手不及” means that something happened by accident and one finds it tough to cope with it. In English idiom, if you catch someone on the hop, you do something when they are not ready for it and may not be able to deal with it well. But it may be difficult for audience to understand the idiom fully.

10) Original: 你不要再花钱打水漂了。

Translation: Stop putting your money into the drain.

As the financial assistant of Wang Duoyu, Xia Zhu suggests that spending money like this would bring him crisis of bankruptcy someday. And “花钱打水 漂” means one use money to invest a set of meaningless things, so the translation "putting your money into the drain" is exactly consistent with the true meaning of it.

11) Original: 你有病吧?

Translation: Are you insane?

When Xia Zhu told Jiannan Liu that he hasn't reported the deposit of two thousand yuan. Jiannan Liu responses by abusing Xia: “Are you insane?". In literary translation, “你有病吧” should be translated into “are you sick” or “are you ill". However, if it is translated like that, the foreign audiences may be misled and puzzled, leading to misunderstanding of the whole sentence. They may think that Jiannan Liu is caring about Xia Zhu while the fact is quite the opposite. Actually Liu thinks that two thousand yuan is such a small amount of money that Wang Duoyu will never remember the subtraction from a billion. And he believes that Xia Zhu is fooled because Wang Duoyu is just completing the challenge given to him by his second grandfather, which requires him to spend a billion yuan in a month so as to get the full heritage. Thus, to avoid the misunderstanding, domestication is employed, and it undoubtedly plays a positive role in helping the audiences to understand the plot of the film.

\subsection{Suggestions for Improvement}
1) Original:
王: 这是要遇贵人呐!
庄: 这人怎么踠这了?
庄: 贵人呐 !
Translation:
Wang: Who knows I will meet my benefactor!
Zhuang: Why is this man kneeling here?
Zhuang: Your benefactor!
Modified Translation: 
Wang: Who knows I will meet my benefactor!

Zhuang: Why is there a kneeling man?

Zhuang: Your leading man!

This sentence is uttered by Wang Duoyu's friend Zhuang Qiang. As Wang Duoyu's car is hit by bird droppings, he jokes that it indicates that he is going to meet his benefactor in his life. Several seconds later, when Wang Duoyu's car stops before the traffic light, a middle-aged man pretended to be hit by the car and then kneels down so as to extort money. Then Zhuang Qiang utters such a sentence like a banter with Wang Duoyu, because in Chinese, “贵” and “趾” have the same pronunciation. Zhuang Qiang is a little amazed at seeing such a benefactor appear kneeling down to extort money from them. Actually, it is one of the punchlines in the film, and Chinese audience can easily get the punchline. However, the original translation fails to indicate the connection between “贵” and “跪” so the sentence loses its original sense of humor, which is against the fidelity rule of skopos theory. Taking this point into consideration, modified translation, replacing "Why is this man kneeling here" with "why is there a kneeling man" and replacing "your benefactor" with "your leading man", not only reveals the connection between "the benefactor" and "the middle-aged man kneeling down to extort money", but also pursues the similar pronunciation "kneeling man" and "leading man", so foreign audience can be able to get the point and feel the specific situation.

2) Original:

王: 因为你叫瞎猪。

夏: 你听好了, 我叫夏竹。

Translation:

Wang: Your name is Xia Zhu, homophone of blind pig.

Xia: Listen carefully, My name is Xia Zhu.

Modified Translation:

Wang: Your name is Xia Zhu, sounds like sharp zoom.

Xia: Listen carefully, my name is Xia Zhu.

The sentence is uttered by Wang Duoyu. At that time, Wang Duoyu is so surprised to find that his personal financial assistant is exactly the woman who sends them into prison because she accuses Wang Duoyu and Zhuang Qiang of bullying in the daylight. He is a little angry and jokes about the assistant's name. In Chinese, Xia Zhu pronounces similar when we say "a blind pig". Here the subtitle translator uses the word "homophone". In linguistics, homophones are words with different meanings which are pronounced in the same way but are spelled differently. However, blind pig does not correspond to the pronunciation of Xia Zhu in English, which violates the fidelity rule. Thus, unlike "blind pig", our modified translation "sharp zoom" not only serves the purpose of employing partial tone, but also indicates that Xia Zhu, in Duoyu's eyes, is a busybody and gossip girl.

3) Original: 
夏: 一个有抱负的老板。

王: 我就是暴富。

Translation:

Xia: and an ambitious leader.

Wang: I am a rich man.

Modified Translation:

Xia: and an ambitious leader.

Wang: I am the richest employer.

In this scenario, Xia Zhu complains that before working for Duoyu, she has worked for another five companies, while all of these companies has closed down or gone bankrupt finally. After complaining, Xia Zhu expresses her wish to seek an ambitious leader. Yet Duoyu responds by saying that he is the one. Although he is not full of ambition, he is rich enough. In Chinese, “抱负”, referring to one who is ambitious, pronounces the same as “暴富”, meaning one who becomes rich overnight. In the original translation, although it successfully conveys the meaning of the content, it loses the rhetoric flavor of the text. For the better manifestation of partial tone, our modified translation employs "the richest employer", which sounds similar to "an ambitious leader", to take the place of "a rich man". In conclusion, the modified translation not only conveys the meaning of the text but also contains a kind of rhetoric flavor.

4) Original: 不吃吐了拿你是问。

Translation: I will kick your ass if they don't vomit.

Modified Translation: I will kick your ass if they aren't stuffed.

This sentence should be translated combining with the domestication strategy, otherwise target audiences cannot appreciate the exaggeration and fun. If “吐” is directly translated into "vomit", which is often related to sickness or illness, it would cause disgusting feeling. Differences between Chinese and western cuisines and table manners is necessary to pay attention to in subtitle translation. In China, it is common for big dishes and eating as more as possible because they are both the symbol of respect for host and guests respectively. And eating one's fill usually brings a sense of satisfaction and happiness. However, in most western countries, they are used to eating in their own dish properly, it is few that a number of people gather together to eat over their appetite. So, "stuffed", conforming to the reasonable extent, is likely to be appropriate for the subtitle translation.

5) Original: 你那点财务还需要助理?

Translation: You're poor, why do you require assistant?

Modified Translation: Personal assistant to manage your poor little money?

The sentence is uttered by Zhuang Qiang. Here Wang Duoyu has just declared that he has got a personal financial assistant, while Zhuang Qiang doesn't believe Duoyu's words. He thinks Duoyu doesn't own much wealth so there is no need for him to have a personal financial assistant. Here Zhou Qiang shows his huge doubt about Wang Duoyu's words. The original translation puts two 
complete clauses in one sentence without a conjunction, so it is grammatically incorrect. Also, by using two clauses, the original translation appears a little wordy and may not well express Zhou Qiang's doubt about Wang Duoyu's claim. Zhuang Qiang's original meaning could be better put by repeating Wang Duoyu's words by an rhetorical question to show his doubt. And the modified translation keeps to the fidelity rule" of skopos theory.

6) Original: 正义会迟到, 但永远不会缺席。

Translation: Justice comes late, but it wouldn't be absent.

Modified Translation: Justice may come late, but it wouldn't be absent.

This sentence is produced by a spectator. Before Wang Duoyu and his friend Zhuang Qiang punished the middle-aged man by bumping him onto the car and this scene is seen by a young woman and other passers-by. They are very indignant to see Wang Duoyu and Zhuang Qiang bullying an ordinary person openly in the daytime. Then one man suggests to put this two arrogant men into prison and another spectator produces this sentence. The translator uses the present tense and the predicative verb in the form of third person singular which is often used to narrate a fact or a truth. But here the character “会” refers to the possibility that sometimes justice will come late, so it is not a fact or truth. Translation uses the modal verb "may" to indicate the possibility so can better express the meaning of the original text.

\section{Conclusions}

Based on research, it can be concluded that colloquialism, popularity, instantaneity and brevity are the four features of subtitle translation, which should not be ignored. Skopos theory gives a guideline for us to the case study of Hello, Mr. Billionaire through using flexible strategies such as reduction and paraphrase for detailed analysis concerning the film subtitle translation. Culture-loaded words are the most important and difficult part, which almost determines the understandings and attitudes of foreign audiences. What we should focus on is to improve the level of subtitle translation constantly so that it can be more understandable to facilitate overseas promotion of Chinese culture.

This study is limited because its analysis of the examples cannot be comprehensive due to the limited time and energy. There is still space for improvement in practice, and constructive suggestions and further study are both welcome.

\section{Conflicts of Interest}

The authors declare no conflicts of interest regarding the publication of this paper.

\section{References}

[1] Baker, M. (2004) Routledge Encyclopedia of Translation Studies. Shanghai Foreign Language Education Press, Shanghai.

[2] Shuttleworth, M. and Cowie, M. (2014) Dictionary of Translation Studies. Rout- 
ledge, London and New York.

[3] 张春柏. 英汉汉英翻译教程[M]. 北京: 高等教育出版社, 2003.

[4] Dollerup, C. (1974) On Subtitles in Television Programmes. Babel, 5, 13-17. https://doi.org/10.1075/babel.20.4.05dol

[5] Fodor, I. (1976) Film Dubbing Phonetic, Semiotic, Esthetic and Psychological Aspects. Buske, Hanburg.

[6] Luyken, G.T., et al. (1991) Overcoming Language Barriers in Television: Dubbing and Subtitling for European Audience. European institute for the Media, Manchester.

[7] Ivarsson, J. (1992) Subtitling for the Media: A Handbook of an Art. Transedit, Simrishamn.

[8] Gambier, Y. and Gottlieb, H. (2001) (Multi)Media Translation: Concepts, Practices, and Research. John Benjamins Publishing, Amsterdam. https://doi.org/10.1075/btl.34

[9] 钱绍昌. 影视翻译——翻译园地愈来愈重要的领域[J]. 中国翻译, 2000(1): 61-65.

[10] Munday, J. (2001) Introducing Translation Studies: Theories and Application. Routeledge, London.

[11] Nord, C. (2001) Translation as a Purposeful Activity: Functional Approaches Explained. Shanghai Foreign Language Education Press, Shanghai.

[12] Reiss, K. and Vermeer, H.J. (1984) Grundlegung einer allgemeinen Translationstheorie. Niemeyer, Tübingen. https://doi.org/10.1515/9783111351919

[13] 张翔. 目的论视角下的《三体》英译研究[D]: [硕士学位论文]. 北京: 外交学院, 2016. 